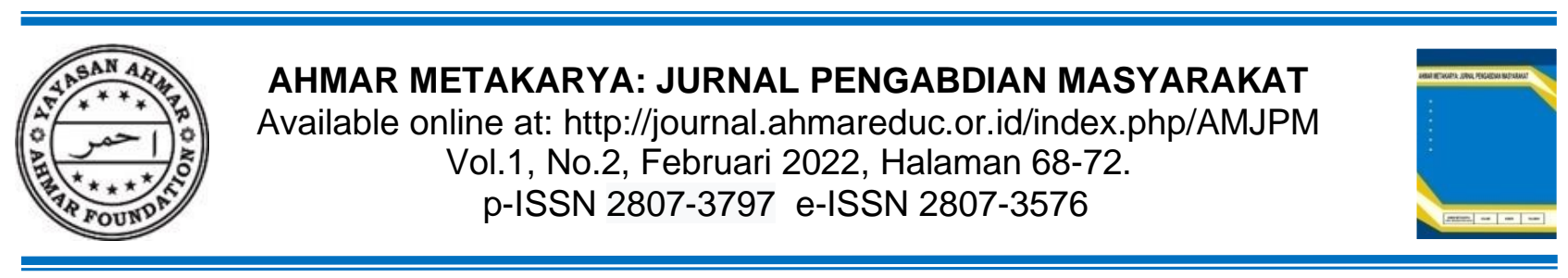

\title{
Pembinaan Kader Posyandu dalam Pencegahan Stunting
}

\author{
Hasmia Naningsih, Khalidatul Khair Anwar*, Aswita \\ Jurusan Kebidanan, Poltekkes Kemenkes Kendari, Kendari, Indonesia \\ *E-mail: khalidatul.megarezky@gmail.com
}

Received: 26 Januari 2022

Accepted: 25 Februari 2022

Published: 28 Februari 2022

\begin{abstract}
Nutritional status becomes very important considering the critical period of growth in the first 2 years is a period for the growth and development of a child. Malnutrition in children is a major public health problem in developing countries, including Indonesia. One of the nutritional deficiencies in children is stunting. The stunting rate in Southeast Sulawesi Province in 2021 was around $30,2 \%$. One of the causes of stunting is the lack of understanding of parents on nutritional intake during pregnancy and the fulfillment of nutrition in infants. Posyandu cadres as one of the closest people to the community have an important role in providing information. However, the provision of health information that really needs to be supported by empowerment or training for posyandu cadres. Based on initial survey data, training for Posyandu cadres in the Soropia Health Center working area regarding stunting had never been carried out. The purpose of the activity is to increase the knowledge of cadres about stunting. The activity involved the coordinating midwife at the Soropia Health Center and the cadres of the Posyandu in Soropia District, which was 20 people as the target of coaching. The results of the service show that the average knowledge pre-test score is 60.00 and the knowledge post-test average value is 90.00 . The results of the work can be obtained by increasing the knowledge of cadres. Therefore, it is hoped that training activities for posyandu cadres can be carried out every year so that cadres can educate mothers and their families so that they can detect early if there is stunting.
\end{abstract}

Keywords: Stunting, Posyandu Cadres, Training.

\begin{abstract}
Abstrak
Status gizi menjadi sangat penting mengingat masa pertumbuhan pada 2 tahun pertama merupakan periode kritis bagi tumbuh kembang seorang anak. Kurang gizi pada anak merupakan masalah kesehatan masyarakat utama di negara berkembang termasuk Indonesia. Salah satu bentuk kurang gizi pada anak adalah stunting. Angka stunting di Provinsi Sulawesi Tenggara pada tahun 2021 adalah sekitar 30,2\%. Salah satu penyebab stunting adalah karena kurang pemahaman orang tua terhadap asupan gizi saat hamil dan pemenuhan gizi pada bayi. Kader posyandu sebagai salah satu orang terdekat masyarakat mempunyai peran penting dalam memberikan informasi. Namun, pemberian informasi kesehatan yang benar perlu didukung dengan adanya pemberdayaan atau pelatihan kepada kader posyandu. Berdasarkan survei data awal, pelatihan kader posyandu wilayah kerja Puskesmas Soropia terkait stunting belum pernah dilakukan. Tujuan kegiatan adalah untuk meningkatkan pengetahuan kader tentang stunting. Kegiatan dengan melibatkan bidan koordinator di Puskesmas Soropia dan kader posyandu Kecamatan Soropia yaitu 20 orang sebagai sasaran pembinaan. Hasil pengabdian menunjukkan rerata nilai pre-test pengetahuan adalah 60,00 dan rerata nilai post-test pengetahuan adalahn 90,00. Hasil pengabdian dapat disimpulkan terjadi peningkatan pengetahuan kader. Oleh karena itu, diharapkan kegiatan pelatihan pada kader posyandu dapat rutin dilakukan setiap tahun agar kader dapat mengedukasi ibu dan keluarganya sehingga dapat mendeteksi dini apabila ada stunting.
\end{abstract}

Kata Kunci: Stunting; Kader Posyandu; Pembinaan. 


\section{A. PENDAHULUAN}

Hasil Survei Status Gizi Balita Indonesia (SSGBI) Tahun 2021 menunjukkan prevalensi stunting sebesar 24,4\% (Kementerian Kesehatan RI, 2021). Angka tersebut menunjukkan bahwa Indonesia masih berada di atas dari target dunia untuk menurunkan prevalensi stunting di bawah $20 \%$. Dengan demikian masih diperlukan program-program dari kementerian dan lembaga untuk bisa mencapai target penurunan stunting pada tahun 2024 yaitu sebesar 14\%. Presiden menekankan program pencegahan stunting agar fokus pada 10 provinsi yang memiliki angka stunting cukup tinggi. Sepuluh provinsi itu: Nusa Tenggara Timur (NTT), Sulawesi Barat, Nusa Tenggara Barat, Gorontalo, Aceh, Kalimantan Tengah, Kalimantan Selatan, Kalimantan Barat, Sulawesi Tenggara, dan Sulawesi Tengah (Kemenkes RI, 2020). Angka stunting di Provinsi Sulawesi Tenggara pada tahun 2021 adalah sekitar 27\% (Wahyu, 2020).

Fenomena dalam upaya pencegahan stunting, kebanyakan masyarakat menganggap faktor keturunan adalah penentu pertumbuhan fisik anak. Anak yang mengalami stunting tidak mudah dideteksi dari penampilan fisik. Anak stunting seringkali terlihat normal dan sehat, sehingga keluarga tidak terlalu memperhatikan gangguan yang terjadi dan penanganan yang harus dilakukan (Kementerian Kesehatan RI, 2019). Anak yang mengalami stunting kebanyakan baru disadari oleh orang tua pada usia 2 tahun ke atas (Direktorat PAUD Kemendikbud, 2021).

Presiden menargetkan angka stunting di bawah 14 persen dalam 5 tahun ke depan, jauh di ambang batas Organisasi Kesehatan Dunia (WHO) yaitu 20 persen (Prasetyo, 2019; World Health Organization, 2014). Menteri Koordinator Bidang Pembangunan Manusia dan Kebudayaan (Menko PMK) Muhadjir Effendy mengatakan, untuk mencapai target 14 persen, maka setiap tahunnya perlu terjadi penurunan sekitar 3 persen (Eko, 2022).

Pemerintah melalui Kementerian Desa, Pembangunan Daerah Tertinggal dan Transmigrasi lewat Permendes No. 11 tahun 2019 tentang Prioritas Penggunaan dana Desa 2020 memasukkan stuntingsebagai program prioritas untuk segera diselesaikan melalui kegiatan konvergensi pencegahan stunting. Dengan mengalokasikan dana desa untuk melaksanakan kegiatan konvergensi dengan harapan bisa mencegah dan menurunkan prevalensi stunting (Kementerian Desa Pembangunan Daerah Tertinggal dan Transmigrasi., 2020). Menkes dalam menanggapi target dari presiden mengaku sudah melakukan observasi di lapangan dan ternyata solusinya cukup mudah. Program Posyandu harus kembali digiatkan lagi. "Kami senantiasa mendukung apapun yang dibutuhkan. Program promotif preventif menjadi bekal di depan, untuk selalu mencegah penyakit, menggiatkan kembali Posyandu, serta memberikan edukasi kepada masyarakat terutama kasus-kasus stunting," kata Menkes (Prasetyo, 2019).

Posyandu mempunyai peran penting sebagai salah satu kegiatan sosial bagi ibu-ibu untuk memantau tumbuh kembang anak. Pemantauan pertumbuhan anak melalui penimbangan balita yang dilakukan secara berkala pada setiap bulannya akan dicatat pada sistem Kartu Menuju Sehat (KMS). Hambatan kemajuan pertumbuhan berat badan anak dapat segera terlihat pada kurva pertumbuhan hasil pengukuran periodik yang tertera dan dicatat pada KMS tersebut. Naik turunnya jumlah anak balita yang mengalami hambatan pertumbuhan dapat segera terlihat dalam jangka waktu pendek (bulan) dan dapat segera diteliti lebih jauh penyebabnya, dan secepat mungkin dapat dibuat rancangan untuk diambil tindakan penanggulangan (Ardiani \& Sudaryati, 2016).

Ketelitian, pengetahuan dan keterampilan kader posyandu dalam melakukan pengukuran antropometri sangatlah penting, karena hal ini menyangkut dengan pertumbuhan balita. Keterampilan kader yang kurang dapat menyebabkan interpretasi status gizi yang salah dan dapat berakibat pula pada kesalahan dalam mengambil keputusan dan penanganan masalah tersebut. Dengan demikian, kemampuan kader harus dikembangkan untuk berpotensi secara maksimal, dengan bekal pengetahuan dan keterampilan yang disesuaikan dengan tugas yang diemban, dalam mengelola posyandu agar dapat berperan aktif dalam meningkatkan kesehatan masyarakat (Handarsari et al., 2015).

Kader kesehatan di desa yang dapat berkolaborasi dengan bidan desa harusnya dapat menjadi motor penggerak dalam mengurangi masalah kesehatan khususnya stunting. Kader kesehatan diharapkan dapat memberdayakan masyarakat dalam mengatasi masalah kesehatan, (Purwati et al., 2018). Pemberdayaan pada kader dalam bentuk pelatihan atau Penyuluhan 
diperlukan untuk meningkatkan pengetahuan kader tentang permasalahan gizi pada masyarakat, khususnya balita sehingga kader kesehatan terpapar informasi baru guna diterapkan dalam pelayanan Posyandu (Priyono, 2022).

Tingginya prevalensi stunting di Provinsi Sulawesi Tenggara menjadi masalah yang penting untuk dicarikan solusi pemecahan bersama. Dinas Kesehatan Provinsi Sultra beserta para pimpinan daerah termasuk pimpinan di Kecamatan Soropia ikut memberikan perhatian pada hal tersebut. Salah satu penyebab stunting adalah karena kurang pemahaman orang tua terhadap asupan gizi saat hamil dan pemenuhan gizi pada bayi. Kader posyandu sebagai salah satu orang terdekat masyarakat mempunyai peran penting dalam memberikan informasi. Namun, pemberian informasi kesehatan yang benar perlu didukung dengan adanya pemberdayaan atau pelatihan kepada kader posyandu. Berdasarkan survei data awal, pelatihan kader posyandu wilayah kerja Puskesmas Soropia terkait stunting belum pernah dilakukan sehingga tim pengabdian Poltekkes Kemenkes Kendari memandang perlu diadakan kegiatan pelatihan pada kader posyandu dalam upaya pencegahan stunting. Tujuan kegiatan pelatihan adalah untuk meningkatkan pengetahuan kader posyandu tentang stunting.

\section{B. METODE DAN PELAKSANAAN}

Metode pelaksanaan kegiatan melalui ceramah dan simulasi. Kegiatan pengabdian kepada masyarakat (PKM) diselenggarakan oleh Tim PKM Jurusan Kebidanan Poltekkes Kemenkes Kendari bekerjasama dengan Kecamatan Soropia dan Puskesmas Soropia. Kegiatan dilaksanakan pada tanggal 16 dan 20 September 2021. Sasaran kegiatan PKM adalah kader posyandu Desa Mekar dan Desa Bajoe dengan masing-masing kader perdesa berjumlah 10 orang sehingga total keseluruhan adalah 20 orang. Adapun tahapan kegiatan adalah sebagai berikut:

\section{Pre-test}

Kader posyandu diminta mengisi kuesioner tentang stunting untuk mengukur pengetahuan awalnya tentang stunting. Kuesioner terdiri dari 15 pernyataan (definisi stunting, cara pencegahan stunting, dan deteksi stunting) dengan skala ukur gutmann

2. Penyajian Materi

Tim pengabdian memberikan materi tentang stunting (definisi stunting, cara pencegahan stunting dan deteksi dini adanya stunting). Tim pengabdi dengan melibatkan mahasiswa mensimulasikan cara yang benar dalam pengukuran $\mathrm{PB} / \mathrm{TB}$.

3. Post Test

Pada tahap ini dilaksanakan 1 minggu setelah kegiatan pembinaan, kader diminta untuk mengisi kuesioner untuk mengukur kembali pengetahuannya tentang stunting.

\section{HASIL DAN PEMBAHASAN}

Kegiatan pemberdayaan yang dilaksanakan pada bulan September 2021 di Desa Bajoe Kecamatan Soropia Kabupaten Konawe merupakan kegiatan yang melibatkan dosen Prodi D-IV Kebidanan Poltekkes Kemenkes Kendari bekerjasama dengan bidan koordinator Desa Mekar dan Desa Bajoe serta aparat desa tersebut. Hasil yang telah dicapai pada saat terselenggaranya kegiatan ini adalah terdapat peningkatan pemahaman kader tentang cara pencegahan stunting dapat dilihat pada tabel 1.

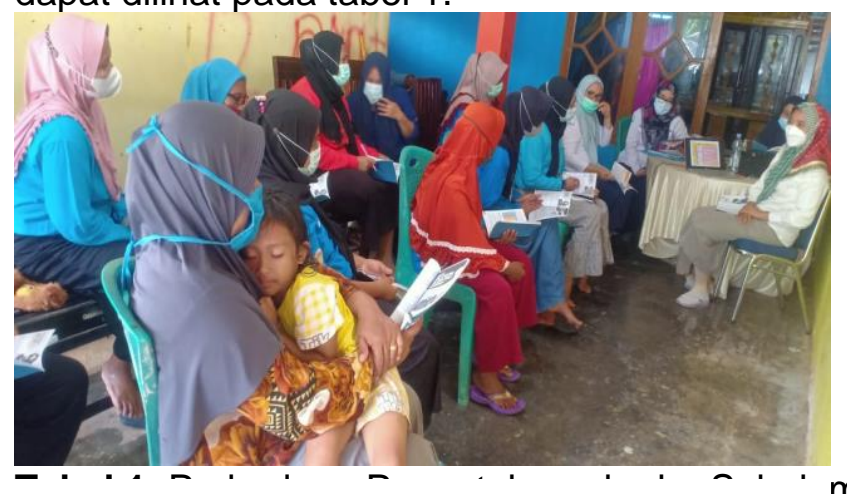

Gambar 1. Pemaparan Materi oleh Tim Pengabdi

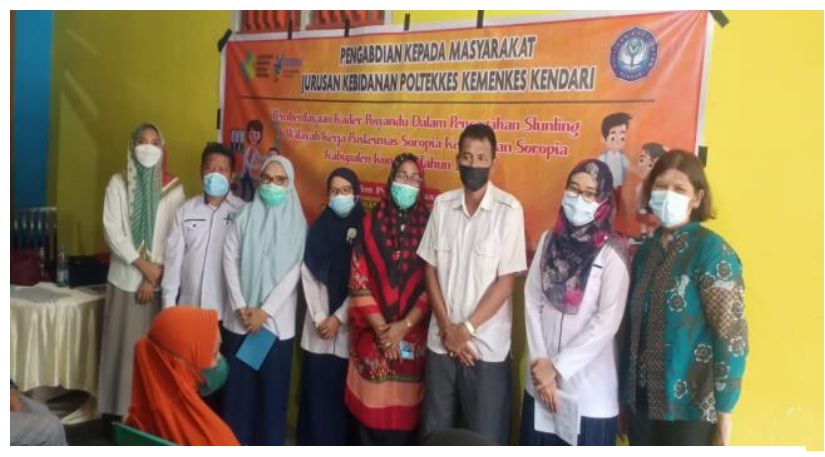

Gambar 2. Foto Bersama Tim Pengabdi, Aparat Desa dan Bidan Koordinator 
Naningsih, H., Anwar, K. K., \& Aswita, A. (2022). Pembinaan Kader Posyandu dalam Pencegahan Stunting. Ahmar Metakarya: Jurnal Pengabdian Masyarakat, 1 (2), 68-72.

\begin{tabular}{ll}
\hline Pengetahuan & Mean \\
\hline Pre Test & 60,00 \\
Post Test & 90,00 \\
\hline
\end{tabular}

Pada tabel 1. menunjukkan bahwa terjadi peningkatan pengetahuan/ pemahaman kader setelah mengikuti kegiatan. Nilai rata-rata pengetahuan kader tentang stunting sebelum mengikuti kegiatan adalah 60,00, kemudian semua peserta mengalami peningkatan dengan rata-rata 90,00 setelah mengikuti kegiatan.

Hasil kegiatan ini sejalan dengan pengabdian yang dilakukan oleh Ningrum et al. (2021) bahwa terdapat peningkatan pengetahuan kader posyandu di Desa Cibeureum Kulon setelah mengikuti pelatihan kader tentang upaya pencegahan stunting pada anak balita. Pemberdayaan kader di Desa Patempuran Kecamatan Kalisat Kabupaten Jember memperlihatkan terdapat peningkatan sebesar 4\% rata-rata pengetahuan tentang stunting serta kandungan gizi pada makanan setelah diberikan penyuluhan (Wicaksono \& Atmaja, 2020).

Peningkatan pengetahuan ibu merupakan salah satu tolak ukur keberhasilan pemberian edukasi/ pelatihan, yang didalamnya terdapat kegiatan belajar mengajar (learning) dari segi kognitif, melalui transformasi informasi yang berurutan pada diri responden. Hal ini sejalan dengan pandangan Santrock dalam bukunya Psikologi Pendidikan yang menyatakan bahwa proses belajar merupakan suatu rangkaian peristiwa/kejadian di dalam diri subjek yang berlangsung secara beruurutan yang dimulai dengan adanya rangsangan/stimulus dan berakhir dengan umpan balik (dalam hal ini pre-posttest) (Santrock, 2011).

Pengetahuan atau kognitif merupakan domain yang sangat penting dalam membentuk tindakan seseorang dan sebagian besar pengetahuan manusia diperoleh melalui mata dan telinga. Informasi juga mempengaruhi pengetahuan karena informasi adalah sebagai pemberitahuan seseorang tentang adanya informasi baru mengenai suatu hal yang memberikan landasan kognitif baru bagi terbentuknya sikap yang baik (Notoatmodjo et al., 2013).

Sumber informasi dapat mempengaruhi tingkat pengetahuan seseorang (Ningtyas, 2015). Dengan adanya komunikasi dengan lingkungan diharapkan akan terjadi perubahan perilaku yang diikuti oleh perubahan lingkungan keluarga dan masyarakat (Anwar et al., 2021). Hal ini sejalan dengan pendapat Notoadmodjo yang menekankan bahwa promosi kesehatan adalah suatu program perubahan perilaku, tetapi juga diikuti dengan perubahan lingkungan, karena perubahan perilaku tanpa diikuti oleh perubahan lingkungan tidak akan efektif dan tidak akan bertahan lama (Notoatmodjo, 2014). Sehingga pendidikan kesehatan melalui pemberdayaan kader merupakan salah satu cara merubah pengetahuan menjadi lebih baik, terarah dan lebih optimal sebagai salah satu pilar safe motherhood dalam menurunkan AKI dan AKB dan untuk mendeteksi dini adanya stunting di masyarakat.

\section{KESIMPULAN}

Kesimpulan dari hasil kegiatan pengabdian kepada masyarakat yang telah dilaksanakan adalah terjalin interaksi antar kader dengan bidan/ tim pengabmas dan terdapat peningkatan pemahaman kader tentang stunting.

\section{UCAPAN TERIMA KASIH}

Terima kasih kami ucapkan kepada Poltekkes Kemenkes Kendari sebagai sponsor dalam mendanai kegiatan PKM. Kami juga mengucapkan terima kasih kepada Aparat Desa, Bidan Koordinator Desa Bajoe dan Mekar, dan para kader yang berpartisipasi aktif dalam kegiatan.

\section{DAFTAR PUSTAKA}

Anwar, K. K., Naningsih, H., \& Patongai, N. (2021). Penguatan Kualitas Pelayanan KIA Melalui Peningkatan Pengetahuan Ibu dengan Pelaksanaan Kelas Ibu Balita 0-1 Tahun. Poltekita: Jurnal Pengabdian Masyarakat, 2(2), 49-53. http://jurnal.poltekkespalu.ac.id/index.php/PJPM/article/view/398

Ardiani, F., \& Sudaryati, E. (2016). Gambaran Keterampilan Kader Dalam Pengukuran BB dan TB Berdasarkan Karakteristik Kader di Wilayah Kerja Puskesmas Langsa Timur Provinsi Aceh Tahun 2015. Gizi, Kesehatan Reproduksi Dan Epidemiologi, 1(1). 
Direktorat PAUD Kemendikbud. (2021, January). Jalan Panjang Pencegahan Stunting. Majalah Paudpedia. $\quad$ https://paudpedia.kemdikbud.go.id/kabar-paud/majalah/jalan-panjangpencegahan-stunting-volume-4-nomor-1-tahun-2021 ?ref=259\&ix=15

Eko. (2022, January 23). Survei SSGBI Tahun 2021 Sebanyak 5.33 Juta Balita Alami Stunting, Target Penurunan 3\% Pertahun. Paudpedia, Kemdikbud. https://paudpedia.kemdikbud.go.id/berita/survei-ssgbi-tahun-2021-sebanyak-533-juta-balitaalami-stunting-target-penurunan-3-pertahun?id=651\&ix=11

Handarsari, E., Syamsianah, A., \& Astuti, R. (2015). Peningkatan Pengetahuan dan Ketrampilan Kader Posyandu di Kelurahan Purwosari Kecamatan Mijen Kota Semarang. Prosiding Seminar Nasional \& Internasional.

Kemenkes RI. (2020). Profil Kesehatan Indonesia Tahun 2019 (Hardhana. Boga, F. Sibuea, \& W. Widiantini, Eds.). Kemenkes RI.

Kementerian Desa Pembangunan Daerah Tertinggal dan Transmigrasi. (2020). Permendesa Nomor 14 Tahun 2020. Kementerian Desa, Pembangunan Daerah Tertinggal dan Transmigrasi. https://peraturan.bpk.go.id/Home/Details/151182/permendesa-pdtt-no-14tahun-2020

Kementerian Kesehatan RI. (2021). Buku Saku Hasil Studi Status Gizi Indonesia (SSGI) Tingkat Nasional, Provinsi, dan Kabupaten/ Kota Tahun 2021. Kementerian Kesehatan RI.

Ningrum, D., Setiadi, D. K., \& Hudaya, A. P. (2021). Pelatihan Kader Posyandu dalam Upaya Pencegahan Kejadian Stunting pada Anak Balita di Desa Cibeureum Pelatihan Kader Posyandu Untuk Pencegahan Stunting pada Balita di Desa Cibeureum Kulon Kecamatan Cimalaka Kabupaten Sumedang. ANDASIH Jurnal Pengabdian Kepada Masyarakat, 2(1), 714. http://jurnal.umitra.ac.id/index.php/ANDASIH/article/view/499/477

Ningtyas, S. F. (2015). Pengaruh Kelas Ibu Balita Usia 0-59 Bulan Terhadap Perilaku Pemanfaatan Buku Kia di Puskesmas Megaluh dan Puskesmas Jogoloyo Kabupaten Jombang. Universitas Airlangga.

Notoatmodjo, S. (2014). Promosi Kesehatan dan Perilaku Kesehatan. Rineka Cipta.

Notoatmodjo, S., Krianto, T., Hassan, A., \& Mamdy, Z. (2013). Promosi Kesehatan Global. Rineka Cipta.

Prasetyo, W. B. (2019). Kader Posyandu Dinilai Bisa Turunkan Stunting. Berita Satu. https://www.beritasatu.com/whisnu-bagus-prasetyo/kesehatan/590863/kader-posyandudinilai-bisa-turunkan-stunting

Priyono, P. K. (2022). Pemberdayaan Kader Posyandu tentang Penanggulangan Stunting pada Balita di Desa Mlese Kecamatan Ceper Kabupaten Klaten. INVOLUSI: Jurnal IImu Kebidanan, 12(1), 6-12. http://ojs.stikesmukla.ac.id/index.php/involusi/article/view/329/186

Purwati, Y., Salmiyati, S., \& Imallah, R. N. (2018). Pendampingan Kader Kesehatan dalam Strategi Produksi dan Promosi MP-ASI. Abdimas Dewantara, 1(2), 96-108.

Santrock, J. (2011). Psikologi pendidikan. In Kencana (Kedua). Kencana.

Wahyu, M. (2020). Tujuh Daerah di Sultra dijadikan Fokus Penangan Kekerdilan. Cendana News. ttps://www.cendananews.com/2020/08/tujuh-daerah-di-sultra-dijadikan-lokus-penanganankekerdilan.html

Kementerian Kesehatan RI. (2019). Warta Kesmas. Kementerian Kesehatan RI. https://www.google.com/url?sa=t\&rct=j\&q=\&esrc=s\&source=web\&cd=\&ved=2ahUKEwi7zvW Dhf71AhVY7XMBHa6WBEEQFnoECBcQAQ\&url=https\%3A\%2F\%2Fkesmas.kemkes.go.id \%2Fassets\%2Fupload\%2Fdir_519d41d8cd98f00\%2Ffiles\%2FWarta-Kesmas-Edisi-12019_1357.pdf\&usg=AOvVaw0qF6rpYWJFsu0kUwKRgpm8

Wicaksono, D. A., \& Atmaja, A. T. (2020). Upaya Pencegahan Stunting Melalui Pemberdayaan Kader Kesehatan di Desa Patempuran Kecamatan Kalisat Kabupaten Jember. JIWAKERTA: Jurnal Ilmiah Wawasan Kuliah Kerja Nyata, 1(2), 35-38. http://jurnalunmuhjember.ac.id/index.php/jiwakerta/article/view/5012/3102

World Health Organization. (2014). Global Nutrition Targets 2025: Stunting Policy Brief. https://www.who.int/publications/i/item/WHO-NMH-NHD-14.3 